Research report

\title{
Changing micronutrient intake through (voluntary) behaviour change. The case of folate
}

\author{
Birger B. Jensen ${ }^{\mathrm{a}, *}$, Liisa Lähteenmäki ${ }^{\mathrm{a}}$, Klaus G. Grunert ${ }^{\mathrm{a}}$, Kerry A. Brown ${ }^{\mathrm{b}}$, Lada Timotijevic ${ }^{\mathrm{b}}$, \\ Julie Barnett ${ }^{\mathrm{c}}$, Richard Shepherd ${ }^{\mathrm{b}}$, Monique M. Raats ${ }^{\mathrm{b}}$ \\ a MAPP Centre for Research on Customer Relations in the Food Sector, Aarhus University, Haslegaardsvej 10, 8210 Aarhus V, Denmark \\ ${ }^{\mathrm{b}}$ Department of Psychology, University of Surrey, Guildford, GU2 7XH, UK \\ ${ }^{\mathrm{c}}$ Department of Information Systems and Computing, Brunel University, Uxbridge, UB8 3PH, UK
}

\section{A R T I C L E I N F O}

\section{Article history}

Received 6 July 2011

Received in revised form 21 February 2012

Accepted 2 March 2012

Available online 9 March 2012

\section{Keywords:}

Behaviour change

Micronutrients

Food choice

Eating behaviour

Folate

\begin{abstract}
A B S T R A C T
The objective of this study was to relate behaviour change mechanisms to nutritionally relevant behaviour and demonstrate how the different mechanisms can affect attempts to change these behaviours. Folate was used as an example to illuminate the possibilities and challenges in inducing behaviour change. The behaviours affecting folate intake were recognised and categorised. Behaviour change mechanisms from "rational model of man", behavioural economics, health psychology and social psychology were identified and aligned against folate-related behaviours. The folate example demonstrated the complexity of mechanisms influencing possible behavioural changes, even though this only targets the intake of a single micronutrient. When considering possible options to promote folate intake, the feasibility of producing the desired outcome should be related to the mechanisms of required changes in behaviour and the possible alternatives that require no or only minor changes in behaviour. Dissecting the theories provides new approaches to food-related behaviour that will aid the development of batteries of policy options when targeting nutritional problems.
\end{abstract}

(c) 2012 Elsevier Ltd. All rights reserved.

\section{Introduction}

Nutritional factors contribute to the risk of many non-communicable diseases as well as to being overweight (WHO report, 2011). In addition to overconsumption of food and suboptimal macronutrient composition of the diet, deficiency of specific micronutrients can create negative health outcomes, such as anaemia or hypothyroidism. Conversely, optimal intake of micronutrients is believed to promote health and well-being, even if the effects may not be directly perceivable by individuals. Recommendations on micronutrient intake aim at providing a reference point for adequate or optimal intake and reaching this intake can be regarded as a desirable goal within a population or sub-population. Setting these reference values is a complicated task, but even if these values are taken as given, identifying the determinants of intake is also difficult. People eat

\footnotetext{
it Acknowledgements: The work reported herein has been carried out within the EURRECA Network of Excellence (www.eurreca.org) which is financially supported by the Commission of the European Communities, specific Research, Technology and Development (RTD) Programme Quality of Life and Management of Living Resources, within the Sixth Framework Programme, contract no. 036196. This report does not necessarily reflect the Commission's views or its future policy in this area.

* Corresponding author.

E-mail address: bbo@asb.dk (B.B. Jensen).
}

food, not nutrients, and making the link between nutrient intake and food-related behaviour requires two processes going in opposite directions; these processes, however, are not symmetric. The desired changes in nutrient intake have to be translated into necessary changes in food intake, but to translate changes in food intake back to nutrient intake requires understanding of the mechanisms of food-related behaviours that are mostly governed by factors independent of their nutritionals consequences (Steptoe, Pollard, \& Wardle, 1995). In this paper the latter process will be unravelled.

From a nutritional point of view, the same micronutrient intake can be reached in different ways and the total composition of the diet (including supplements) determines how well individuals within the population reach the recommended intake. If dietary surveys suggest that current intake is a possible cause of negative health outcomes, policy makers need to consider different options that could improve the situation. One such option is the possibility of inducing changes in individuals' food-related behaviours (either as a single strategy or as one part of a broader suite of measures such as for instance fortification initiatives). Changing behaviour requires that the relevant food behaviours are identified and their determinants understood.

Folate was chosen as the target micronutrient for this paper, because folate intake is currently widely discussed and offers a useful arena for demonstrating the complexity of behaviours that can be related to increasing the intake of a single micronutrient. 
There is an additional requirement for folate before and during pregnancy to reduce the risk of foetal neural tube defects, such as spina bifida (Locksmith \& Duff, 1998). Current UK recommendations, for example, advise adults to consume a varied balanced diet in order to maintain adequate folate levels, whereas women of child bearing age are advised to take a daily folic acid supplement of $0.4 \mathrm{mg}$ from the time they stop using contraception to the 12th week of pregnancy (Food Standards Agency, 2003).

Traditionally, desired behaviour changes are induced by aiming at individuals' voluntary behaviour changes via education or social marketing campaigns, with much less emphasis on the environmental prerequisites that may promote desired behaviour changes (Hoek \& Jones, 2011; Michie, van Stralen, \& West, 2011). Related to folate intake, there are recent studies on testing the effectiveness of campaign messages (Lindsey et al., 2009), of radio and television spots in promoting supplements for women (Warnick et al., 2004), or promoting intake of folate among vulnerable consumer groups in Florida both by education and by providing folic acid supplementation (Thomas, Hauser, Rodriguez, \& Quinn, 2010). Indeed, there is evidence that food fortification may be a more effective way to prevent folate deficiency and its negative health outcomes (Solomons, 2007).

The objective of this paper is to relate behaviour change mechanisms to nutritionally relevant behaviour by using folate intake as an example to demonstrate how the different mechanisms can affect attempts to change these behaviours. First, eating behaviour in relation to micronutrient intake is explored in order to recognise the possible behavioural changes that have an impact on folate intake. Second, appropriate mechanisms of behaviour change are identified and extracted from different theories and models and then aligned against the possible impacts on folate intake to illuminate the possibilities and challenges in inducing behaviour change. Finally, the applicability of these behaviour change mechanisms in changing micronutrient intake through voluntary behaviour change is discussed.

\section{Micronutrient intake and food-related behaviour}

Although appearing deceptively simple, food-related behaviours are complicated actions governed by a mix of cultural conventions, social interaction, individual perceptions and physiological influences (Blake, Bisogni, Sobal, Devine, \& Jastran, 2007; Rozin, 2007). Sobal and colleagues (1998) divide the food and nutrition system into three subsystems: producer, consumer and nutrition, pointing out the separate, but closely interlinked, systems of food acquisition and intake. Overall, micronutrient intake is a nutritional measure, but several steps are required in order to reach a certain intake. Having become aware of the need to increase the intake, the potential sources of the targeted micronutrient must be recognised and then it must be assessed whether and how the intake of these foods can be in- or decreased in the diet (Fig. 1). Furthermore, the link between food and nutrient intake is complex as many food choices are interrelated and not chosen in isolation from each other (Sjöberg, Hallberg, Höglund, \& Hulthen, 2003). One food added to the diet may replace another, or the omission/addition of a food often eaten in combination with another food would subsequently mean omitting or adding the other one as well. Thus, the net influence of a seemingly straightforward recommendation to add a single food in a diet may result in lower or higher intake change than anticipated. Changing the intake of one micronutrient is challenging, but in reality the intake of several micronutrients must be considered to make sure that changes linked to one micronutrient are not counterproductive in relation to other micronutrients.

The process of eating behaviour leading the micronutrient intake is presented in Fig. 1. Foods available in the choice situation determine an individual's access to particular micronutrients. The preparation required before the food is edible may, however, also influence the micronutrient content. For instance, storage and preparation methods may decrease the amount of micronutrients in foods (Fillion \& Henry, 1998; Severi, Bedogni, Manzieri, Poli, \& Battistini, 1997). Eating occasions vary from unstructured to structured: e.g. for snacking there are few rules about what should be eaten and when, whereas meals tend to follow predefined conventions and rules related to combining foods and scheduling meals (Blake et al., 2007; Mäkelä, 2001). Some suggested changes in choices may fit into existing practices whereas others require major modifications in the composition of the meal. Exchanging one type of vegetable for another may be easier than adding a vegetable as a second side dish to the meal, because the latter strategy may require omitting another option from the meal or putting extra effort into preparing an additional component to the meal. Table 1 lists examples of behaviour changes that have an impact on folate intake.

Eating behaviour is further complicated by individuals eating varying amounts of the purchased and prepared food resulting in an uneven distribution of micronutrient intake among household members. Furthermore, some of the food bought is not consumed and the waste can vary across products. It is estimated that in the UK up to 6.8 million tonnes of the food bought for household consumption ends up as waste, particularly vegetables, fruit, and bread (WRAP, 2009).

One way of bypassing the complexity of eating behaviour is to opt for micronutrient-containing supplements. Yet, paradoxically, the use of supplements seems to be more common among those whose dietary habits can be categorised as healthy (Dwyer et al., 2001). Thus, though seemingly an easier route to provide micronutrients to consumers, current practice suggests that those more in need of supplements may be unaware of their need, or of the possibility of supplementing their diet in this way, or they may lack the motivation to do so.

In summary, when considering possible policy options, the feasibility of obtaining the desired outcome should also be considered in relation to the mechanisms of the required changes in behaviour. To have an impact on micronutrient intake, not only should food choice behaviours that contribute to the accessibility of good sources of micronutrients at home and food services be targeted, but also the determinants of intake and food-related practices in households. Although supplements may offer an alternative, simpler route to complement dietary micronutrient intake, the possible barriers to this approach should also be considered.

The present paper explores how to achieve an increase in the intake of folate, especially among women of fertile age, by voluntary changes of behaviour rather than by changing the food supply (e.g. fortification). After awareness has been raised, the required changes include a wide range of separate actions in purchases (choice behaviour), eating patterns, storage conditions used and cooking methods (Table 1 ). Because individuals vary in their eating patterns, the changes required and the need for supplements will also vary across individuals. Changes in different behaviours differ in their efficacy to increase folate intake and the impact of the changes needs to be assessed against the feasibility of the behaviour change.

\section{Behaviour change mechanisms}

Inducing changes in food-related behaviour can be based on a range of models and theories that contain a limited number of behaviour change mechanisms, some of which may be overlapping. Previous studies have identified and categorised a number of behaviour change mechanisms (e.g. Fishbein et al., 2001; Michie et al., 2005). In the present paper the major approaches used are 


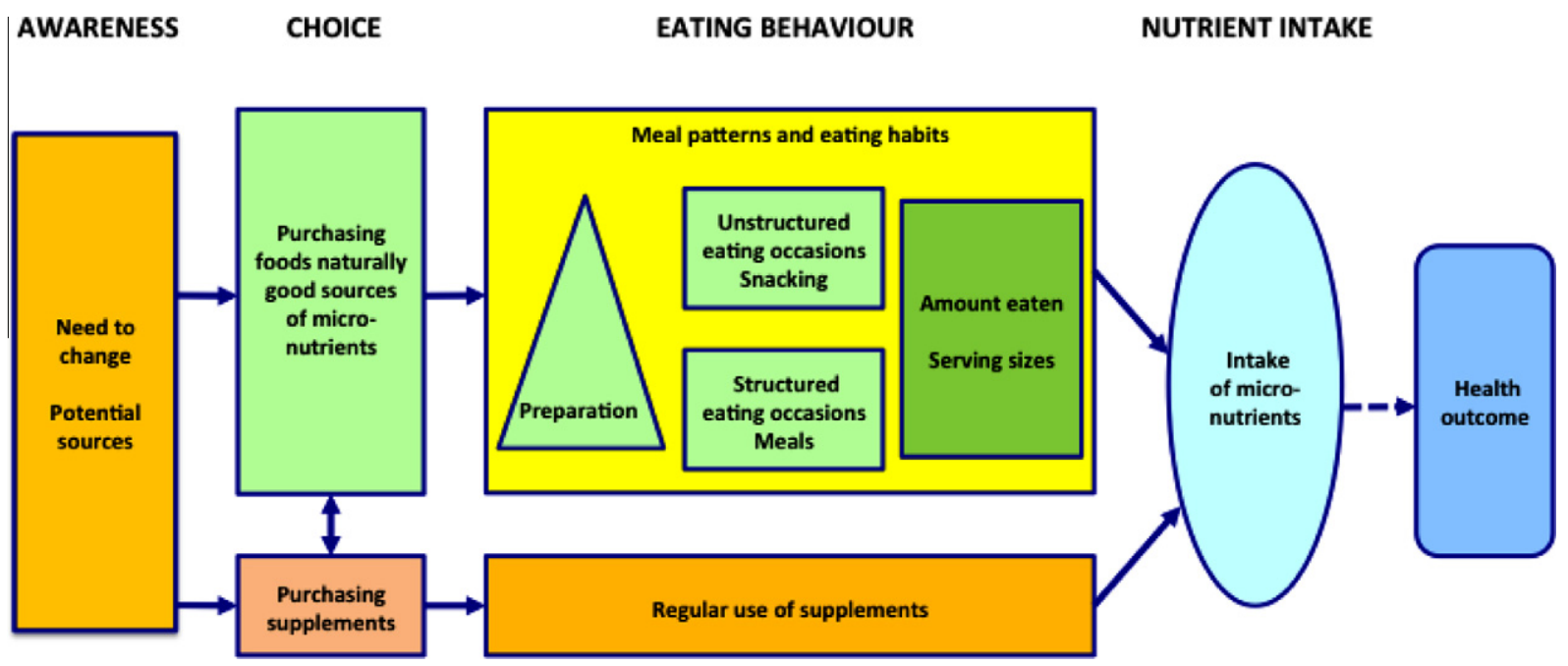

Fig. 1. Process of eating behaviour contributing to the micronutrient intake.

Table 1

Examples of behaviour changes related to changes in folate intake.

Choices - availability for the individual

- Purchasing/choosing foods that are naturally good sources of folates (e.g. green vegetables, dried beans, liver and whole grain products)

- Purchasing/choosing products fortified with folic acid

- Purchasing supplements containing folic acid (in the form of pills, capsules or herbal preparations)

Meal patterns and eating habits - intake

- Switching from refined grain products to whole grain products

- Increasing use of whole grain products as snacks

- Including green vegetables and dried beans in meals

- Adoption of new storage conditions, recipes and cooking methods that conserve the folate content

- Switching to fortified products

- Taking supplements regularly

examined, including the "rational model of man", behavioural economics, health psychology, and social psychology. Behaviour change mechanisms are extracted from these (see Table 2). The literature on factors influencing human behaviour is enormous (Maio et al., 2007). From this vast volume of work, the aim has been to identify the mechanisms which are the most relevant in a food context and which can be targeted to induce changes at the wider population level. As such, the list of mechanisms is not exhaustive and may lack some obvious ones. For instance, behaviour change mechanisms that are used in individual counselling have been omitted (Spahn et al., 2010), e.g. those from Cognitive Behavioural Theory (Beck, 1976), because, due to its cost, counselling rarely is an option when aiming at changes at the wider population level.

The mechanisms listed in Table 2 include most of those identified in the context of promoting HIV preventive behaviour by Fishbein and colleagues (2001), who suggested that intentions, environmental constraints and skills are necessary and sufficient prerequisites for the performance of any behaviour, whereas the other five mechanisms in their list (anticipated outcomes/attitude, norms, self-standards, emotion, and self-efficacy) can be viewed as moderators of the strength and direction of the intention. In the present paper their list has been supplemented by considering mechanisms related to habits (Verplanken \& Wood, 2006; Wood \& Neal, 2009), stage theories (Prochaska \& DiClemente, 1983; Schwarzer, 2008) and goal setting (Gollwitzer, 1999; Gollwitzer \& Brändstatter, 1997).

As illustrated in Fig. 2, behavioural outcomes can be the result of conscious processes and intentions (Sections 1-3), or of habits (Section 4) that bypass these processes and lead directly to behaviour (Triandis, 1977; Verplanken \& Wood, 2006). The conscious processing path starts with awareness, information processing and belief formation. Awareness can increase information seeking, but several cognitive mechanisms may interfere with people's information processing and thus ability to make strictly reasoned decisions. According to most socio-psychological models, adopted beliefs serve as input to conscious processing of pros and cons, social norms and self-efficacy, which may result in an intention to change food-related behaviour. Socio-psychological models have been criticised for not addressing how to maintain good intentions (Schwarzer, 2008), which may help explain the "intention-behaviour gap" that has been observed again and again (Schwarzer, 2008; Sheeran, 2002). Stages of change models and goal-setting theories explicitly acknowledge the need for planning and behaviour maintenance in the post-intentional phases to facilitate long-lasting behaviour change (Section 3 in Table 2). Repetition of intentional behaviour may eventually lead to food-related habits that are automatically triggered responses to environmental cues. The last section of Table 2 concerns mechanisms relating to how habits are formed and broken down. Below, each of the mechanisms identified in relation to the folate example will be discussed.

\section{Awareness of folate and information processing}

Being aware of a problem or recognising a need to change is a starting point for seeking solutions and making volitional changes in one's behaviour. Awareness of folate recommendations and how to comply with them may be raised by providing information. Beliefs are acquired and changed through a learning process. Learning may take place through active information seeking and/ or passive information acquisition. Economic theory acknowledges that people may not be fully aware of the consequences of their 
Table 2

Mechanisms of behaviour change.

\begin{tabular}{|c|c|}
\hline $\begin{array}{l}\text { Behaviour change mechanisms facilitating/ } \\
\text { mitigating change }\end{array}$ & $\begin{array}{l}\text { Major theories/models } \\
\text { where the behaviour } \\
\text { change mechanism is used }\end{array}$ \\
\hline \multicolumn{2}{|l|}{ 1. Mechanisms affecting belief formation } \\
\hline Cognitive mechanisms & $\begin{array}{l}\text { E.g. Behavioural economics, } \\
\text { Social psychology }\end{array}$ \\
\hline \multicolumn{2}{|l|}{ Attentions bias } \\
\hline \multicolumn{2}{|l|}{ Optimistic bias } \\
\hline \multicolumn{2}{|l|}{ Hyperbolic discounting } \\
\hline \multicolumn{2}{|l|}{ Cognitive dissonance } \\
\hline \multicolumn{2}{|l|}{ Loss aversion/Framing } \\
\hline \multicolumn{2}{|l|}{ Heuristics } \\
\hline \multicolumn{2}{|l|}{ 2. Mechanisms of intention formation } \\
\hline \multicolumn{2}{|l|}{ Decisional balance } \\
\hline $\begin{array}{l}\text { Pros and cons/cost-benefit/outcome } \\
\text { expectancies }\end{array}$ & $\begin{array}{l}\text { Rational model of man", } \\
\text { SCT }^{\mathrm{a}}, \mathrm{HBM}^{\mathrm{b}}, \mathrm{PMT}^{\mathrm{c}}, \mathrm{TTM}^{\mathrm{d}} \text {, } \\
\text { HAPA }^{\mathrm{e}}\end{array}$ \\
\hline Attitudes & $\mathrm{TRA}^{\mathrm{f}}, \mathrm{TPB}^{\mathrm{g}}, \mathrm{TIB}^{\mathrm{h}}$ \\
\hline Motivational factors & E.g. $\mathrm{HBM}^{\mathrm{b}}$ \\
\hline \multicolumn{2}{|l|}{ Social influences } \\
\hline Subjective norms, injunctive norms & $\mathrm{TRA}^{\mathrm{f}}, \mathrm{TPB}^{\mathrm{g}}, \mathrm{TIB}^{\mathrm{h}}$ \\
\hline Model learning, descriptive norms & $\mathrm{SLT}^{\mathrm{i}}, \mathrm{SCT}^{\mathrm{a}}$ \\
\hline \multicolumn{2}{|l|}{ Control mechanisms } \\
\hline (Action) self-efficacy & $\mathrm{SCT}^{\mathrm{a}}, \mathrm{PMT}^{\mathrm{c}}, \mathrm{TTM}^{\mathrm{d}}, \mathrm{HAPA}^{\mathrm{e}}$ \\
\hline Perceived behavioural control & $\mathrm{TPB}^{\mathrm{g}}$ \\
\hline \multicolumn{2}{|l|}{ 3. Adopting and maintaining behaviour } \\
\hline Coping and recovery self-efficacy & $\mathrm{HAPA}^{\mathrm{e}}$ \\
\hline \multicolumn{2}{|l|}{ Planning and goal setting } \\
\hline Implementation intentions & E.g. Gollwitzer (1999) \\
\hline Action and coping planning & $\mathrm{HAPA}^{\mathrm{e}}$ \\
\hline \multicolumn{2}{|l|}{ 4. Habits and routines } \\
\hline Accumulated experience with behaviour & $\mathrm{TIB}^{\mathrm{h}}$ \\
\hline Strength of habit & $\begin{array}{l}\text { E.g. Verplanken and Wood } \\
\text { (2006) }\end{array}$ \\
\hline $\begin{array}{l}\text { Change in contextual factors, } \\
\text { e.g. environmental cues }\end{array}$ & $\begin{array}{l}\text { E.g. Verplanken and Wood } \\
\text { (2006) }\end{array}$ \\
\hline Life-transition stages/imposed changes & $\begin{array}{l}\text { E.g. Chapman and Ogden } \\
\text { (2009) }\end{array}$ \\
\hline
\end{tabular}

\footnotetext{
a SCT = Social Cognitive Theory

b $\mathrm{HBM}=$ Health Belief Model

c $\mathrm{PMT}=$ Protection Motivation Theory

d TTM $=$ Trans-Theoretical Model of change

e HAPA = Health Action Process Approach

f TRA = Theory of Reasoned Action

g $\mathrm{TPB}=$ Theory of Planned Behaviour

h $\mathrm{TIB}=$ Theory of Interpersonal Behaviour

i SLT = Social Learning Theory
}

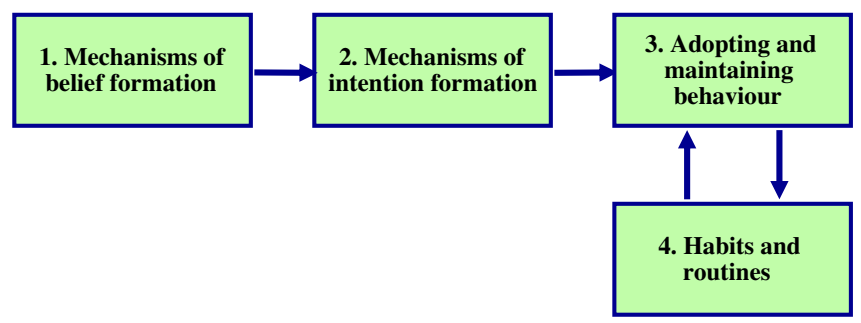

Fig. 2. Illustration of the relationship between behaviour change mechanisms.

behaviour and possible solutions, but assumes they will search for and process additional information (if provided to them at no cost), which subsequently may affect their beliefs. Stage models, like the Precaution Adoption Process Model (Weinstein \& Sandman, 1992) and the Trans-Theoretical Model of change (Prochaska \& DiClemente, 1983; Prochaska \& Velicer, 1997), recognise the need to provide information about the possible health risks to shift people from being unaware (or under-aware) of an issue to being aware.

Information is necessary but not sufficient to increase awareness among the target population. Due to attention bias people tend to favour messages they find personally relevant and in order for information to have an impact, women of fertile age should both be aware of the problem and recognise themselves as belonging to the target group. Awareness of the increased need for folate before and during early stages of pregnancy may result in different motivational states depending on whether one is planning to get pregnant or not. For women planning pregnancy, searching for information may be an active part of preparation. Women trying or planning to get pregnant are more likely to actively seek and process information about prenatal health. Accordingly, this group of women may not only be well aware of the folate issue and foods that are naturally good sources of folate, but also highly motivated to look after their own health and that of their unborn child. According to the Health Belief Model (Rosenstock, 1974), motivation is an important factor in health-promoting behaviours and therefore this group is likely to be more responsive to information about folate and more attentive to possible routes to reach the recommended intake. Even when women plan pregnancy, they may not consider themselves as belonging to the target group because they may perceive their folate intake to be higher than the intake of women on average, or that their risk of neural tube defects in their newborns is lower than for mothers in general. Research refers to this cognitive mechanism as optimistic bias (Weinstein, 1984) and the consequence may be that these women disregard related health risk messages.

One of the challenges in inducing behaviour change, in particular among women not actively planning pregnancy, is hyperbolic discounting. This relates to the fact that people tend to balance the information about long-term benefits against short-term rewards and this calculation results in a discount rate (Shapiro, 2005). Hence, as seemingly the risks are remote, these women may perceive the long-term benefits of maintaining an adequate folate intake as less rewarding when balanced against the immediate benefits of not preventing the folate deficit (e.g. saving money and less required effort).

Cognitive dissonance occurs when individuals hold beliefs that are inconsistent, or when individuals' actions and beliefs are inconsistent (Festinger, 1957). Individuals experiencing cognitive dissonance are assumed to take steps to reduce it, either (a) by changing beliefs or actions to achieve consistency, or (b) by adopting new beliefs that overpower the dissonant belief (confirmatory bias) (O'Keefe, 1990). To mitigate discounting, Aronson's hypocrisy inducing technique (1999) may be used to promote choosing foods high in folate. Future mothers may be confronted with the assertion that they are likely to want the best for their unborn child, which requires changes in their practices. A possible discrepancy should result in an uncomfortable state, perhaps even feelings of shame, which may induce these women to actually seek information about the good sources of folates to avoid the cognitive dissonance associated with their actions on the one hand and their self-image as a caring parent on the other.

\section{Choosing and purchasing foods naturally good sources of folate}

Choosing foods naturally high in folates can be divided into relatively clearly defined behaviours (Table 1 ), but different factors may promote or hinder these behaviours as they are related to foods that have different roles in our eating behaviour. The feasibility of behaviour change can be assessed by using the Theory of Planned Behavior (TPB) (Ajzen, 1991) as a framework and studying the role of attitudes, subjective norms and perceived behavioural control in predicting the likelihood of women's intentions to purchase folate-rich foods.

According to most models of behaviour, it is assumed that people decide which foods to purchase by balancing costs and benefits. Thus, if women perceive a net benefit from increasing their folate intake, it 
is more likely that they will be motivated to purchase folate-rich foods. This weighing of pros and cons of a change in behaviour can be termed as the decisional balance, or attitude towards the behaviour. Attitudes are a function of beliefs about the consequences of the behaviour weighted by an evaluation of each outcome. However, as described in the previous section, the cognitive mechanisms affecting belief formation will play a role in assessing the possible outcomes of behaviours. Strong positive beliefs paired with strong negative beliefs reflect a degree of attitudinal ambivalence. In relation to food choice, studies have demonstrated that people with higher ambivalence in their beliefs show less consistency between attitudes and behaviour (Conner, Povey, Sparks, James, \& Shepherd, 2003; Conner et al., 2002). If people believe that it is important to ensure sufficient folate intake by buying whole-grain products, but at the same time they are averse to the palatability of wholegrain products thus doubting whether the household will actually eat them, it is difficult to predict the behavioural outcome.

Some outcome expectancies may be strongly linked to affective and emotional responses. Future mothers' perceived risk of foetal neural tube defects in their new-borns may be associated with fear. Affective responses and emotions can be regarded as independent factors influencing behaviour as in Theory of Interpersonal Behavior (TIB) (Triandis, 1977),or considered as the affective beliefs behind attitudes resulting in considerable overlap between attitude and emotion (Fishbein et al., 2001).When anticipating positive and negative self-sanctions, such as feelings of fear, delight, anxiety and repulsion, they can be viewed as outcome expectancies having an impact on decisional balance.

Subjective norms act as a guide to how people think that others expect them to behave and may therefore facilitate or mitigate increased folate intake. People tend to comply to some degree with what those who are important to them want them to do (Ajzen \& Fishbein, 1980). In addition to subjective norms, injunctive norms refer to an individual's appraisal of the overall social support for certain behaviours within a culture (Cialdini, Kallgren, \& Reno, 1991). Injunctive norms may promote choosing foods high in folate if it is perceived to be what is expected of a young woman and the right thing to do in one's social and cultural environment. However, injunctive norms may also act as barriers to behaviour change: if the norm does not support the purchase of folate-rich foods, for instance the apparently higher social status of refined grain products may act as an injunctive norm.

Another social influence is based on vicarious learning. According to Social Learning Theory (Bandura, 1977a), people tend to base their behaviour on "model learning", which is closely related to descriptive norms, i.e. perceptions of what most other people do, or what they believe is commonly done. In campaigns promoting folate intake, famous people, or people who are similar to the target group (and therefore easy to identify with), can be used as role models for increasing folate intake.

The last mechanism derived from TPB is perceived behavioural control, which is predicted partly by beliefs about one's capability to perform behaviour and partly by beliefs about environmental constraints, such as resource availability. Thus, the environment must provide an opportunity, or be free of constraints, for realising the desirable behaviours. In relation to this, some women may perceive the availability and price level of folate-rich foods as insurmountable barriers to purchasing such foods, which again may result in low perceived behavioural control.

Perceived behavioural control is closely related to the concept of self-efficacy, which is the central element of Social Cognitive Theory (Bandura, 1997c). Self-efficacy refers to the confidence in one's capability to perform a desired behaviour in different situations (Bandura, 1977b, 1997c). People with higher self-efficacy are more motivated to change, will put more effort into their attempts to change, and will have a better chance of succeeding. Although perception of one's capabilities may not always reflect a realistic representation of the actual capability, it can nevertheless act as a motivator for change. Due to its dynamic nature, self-efficacy evolves over time as success adds to a sense of self-efficacy, whereas failure in changing behaviour can reinforce the perception of low self-efficacy. Hence, two women who have the same knowledge of natural sources of folate may differ in their capability to use this information in their purchase behaviour.

When making changes in food choices, the elaborate weighing of pros and cons does not always take place, because it requires effort. Prospect theory (Kahneman \& Tversky, 1979) describes how people are averse to risk of loss and thus reluctant to depart from status quo. For instance, omitting foods associated with hedonic pleasure from the shopping list to make room for green vegetables and dried beans may be perceived as a loss. The decisions made by individuals may depend on how the choices available are presented to them. Framing the choices in terms of loss instead of gain can alter the decisions made, as can presenting the items in a different order. If the aim is to promote increased intake of folate, the outcome may be framed either as reducing the risk of foetal neural tube defects or as promoting the health of future offspring thereby being a caring mother. Bounded rationality (Simon, 1982) takes the complexity of everyday decisions (e.g. choice overload and clutter) into account stating that people use cognitive short cuts, heuristics to reduce the effort as a response to the cost of obtaining and processing full information. As a consequence, simple heuristics may be promoted in order to alter beliefs about barriers to choosing the right foods, e.g. "the greener, the better".

\section{Meal patterns and eating habits}

A precondition for increasing intake of folate is purchasing foods that are naturally good folate sources. Availability in the household is, however, no guarantee that these food items will actually be consumed in sufficient quantities by individuals in need of increasing their folate intake. A number of barriers related to meal patterns and habits may emerge.

One could assume that unstructured eating occasions offer easier options to promote folate intake because they are less rulebound than meals. It may be relatively easy to include products rich in folate (e.g. whole-grain products) as snacks. Yet foods bought and consumed on the spot may be strongly influenced by subjective norms that are related to other people's presence and expectations in that situation as described earlier in the section on food choices. Whole-grain snacks would fit nicely after sports for instance, but the norms of one's surroundings may inhibit eating of whole-grain snacks and thus function as a barrier to increasing one's folate intake.

In addition to continuum models like TPB assuming that the same factors influence behaviour regardless of the type of behaviour, Prochaska and DiClemente (1983) introduced a model that distinguishes different stages in the change process based on their experience with smokers quitting their habit. The Health Action Process Approach(HAPA) (Lippke, Ziegelmann, \& Schwarzer, 2004; Schwarzer, 2008) combines the stage and continuum models and suggests that a change in behaviour is more likely to happen if intentions are transformed into detailed instructions on how to perform the desired action. In the case of folate, this means planning shopping lists and meals that contain folate-rich components. The post-intentional phase in HAPA incorporates action planning (when, where and how to act (Gollwitzer \& Sheeran, 2006)) and coping planning (the generation of alternative behaviours to overcome anticipated barriers (Schwarzer, 2008; Sniehotta, Scholz, \& Schwarzer, 2005) as mediators of intentions and behaviours. Several authors have found evidence for phase-specific self-efficacy beliefs (Bandura, 1997c; Luszczynska \& Schwarzer, 2003; Schwarzer \& Renner, 2000), 
which suggests that some people may be relatively good at planning changes, but are challenged in maintaining the behaviour or taking correcting actions when failing to go through with the actions planned. As such, planning such coping may aid the formation of strong beliefs about how to deal with barriers arising while adopting or maintaining a new behaviour (coping self-efficacy), or getting back on track after a potential setback (recovery self-efficacy). In the case of unstructured eating occasions with friends, one may anticipate and plan how to cope with reactions from friends as well as how to avoid a setback due to temptations while, for instance, snacking together in the sports cafeteria. Action planning may also be required in order to turn good intentions into consuming the 'right' foods, e.g. by planning where and when to purchase and when to bring a whole-grain snack.

Folates, however, mostly appear in foods that are part of structured eating occasions. Conventions for constructing meals provide a specific room for green vegetables and dried beans on the plate. Firstly, vegetables must be an integral part of a meal; otherwise the behaviour change requires the household to re-assess their habitual meal concept. Secondly, if certain vegetables are included, they may need to be exchanged for ones providing folates, which may require self-efficacy in preparing and storing the leafy vegetables. It is estimated that in the UK up to $50 \%$ of green vegetables bought for household consumption actually goes to waste (WRAP, 2009). In families, other household members' negative attitudes may act as an insurmountable barrier against including leafy vegetables in the meal. This may require coping planning in order to increase beliefs that support coping self-efficacy, e.g. deliberately deciding to ignore others' opinions.

Planning in HAPA is related to implementation intentions (Gollwitzer, 1999; Gollwitzer \& Brändstatter, 1997) that form cognitive links between situational circumstances or opportunities and the goal behaviour. Goals do not induce actions directly, but they may lead to highly specific plans, which in turn induce actions through mental simulation of success scenarios (Gollwitzer, 1999). Thus, promoting the use of meal plans and cooking skills that provide foods sufficiently high in folates may be one way of promoting action and coping self-efficacy thus transforming the good intention into a long-lasting behavioural change.

If habits are very strong, good intentions may fall short and even implementation intentions may not be sufficiently powerful to change behaviour (Verplanken \& Faess, 1999). According to Triandis' (1977) Theory of Interpersonal Behavior, accumulated experience with a behaviour results in increased influence from habit and decreased influence of intention. Habitual behaviour becomes detached from the original motivating factors. Thus, changing those factors (e.g. attitudes and intentions) will not necessarily change the habit as their power to influence the behaviour has diminished. Verplanken and Wood (2006) argue that habits may develop as environment-response associations that gradually become stronger in memory with repeated experience. Consequently, habitual responses may be triggered automatically by environmental cues (Ouelette \& Wood, 1998; Wood \& Neal, 2009), e.g. meals are repeated at the same time in the same pattern without giving any thought to the content. If the family's habitual meal concept leaves no place for green vegetables and dried beans, promoting increased folate intake may fall short if not tailored to the habit strength. Thus, such strong habits cannot be changed by influencing women's decisional balance (e.g. through informational campaigns). Rather they require changes in the environmental cues, e.g. lower prices due to subsidisation of folate-rich food products, active promotions by food suppliers in specific use contexts, or addressing social norms supporting habits (McKinlay, 1975, 1993).

Wood and colleagues (2005) have observed that established routines can be broken and new ones formed at certain life-transition stages. Verplanken and Wood (2006) suggest that health promotion activities should take advantage of this. Accordingly, health interventions targeted at certain life-transition stages, where people need to adapt to changes in their environment, may stand a better chance of changing habitual behaviours. For instance, families may be more responsive to changing habits, which otherwise mitigate (voluntarily) increasing folate intake, at life-transition stages, such as when planning a pregnancy (Wood, Tam, \& Guerrero Witt, 2005). Health professionals and family planning clinics might be effective in imposing behaviour changes in these transition situations. Chapman and Ogden (2009) address a passive path to behaviour change, in which diet changes happen to people without them initiating the change, although they are aware of it. Imposed changes due to changing life circumstances fall into this category. If a workplace canteen, for example, decides to add more green vegetables and whole-grain products to the menu offered to its employees, this may impose an increase in folate intake.

\section{Purchasing and regular use of supplements}

It may not always be feasible or practical to increase folate intake through one's diet, because the quantity of, for instance, green vegetables one needs to eat is simply too large or too difficult to integrate into one's meal patterns. An alternative to changing food choices and eating patterns is to take folic acid as a supplement. This requires less of an effort than altering one's eating patterns, but taking a supplement regularly still means that an individual needs to establish a new routine. Thinking how and when to take the supplement can be described as implementation intention planning (Gollwitzer, 1999). For instance, eating a supplement every morning before breakfast links the behaviour to environmental cues and establishes a habitual new routine. However, implementation intentions are more useful when forming new habits than countering existing strong habits automatically cued by contexts (Verplanken \& Faess, 1999).

There are also pros and cons to consider when opting for a folic acid supplement. When focusing on folates in the diet, one is likely to get other beneficial compounds as well from the good sources of folates. Supplements guarantee the sufficient intake if taken according to recommendations, but on the other hand they may be costly and perceived as taking the easy option, which may not correspond to the subjective or injunctive norms that other people in one's community regard as responsible eating behaviour. In addition, among young girls not actively planning pregnancy, taking a folic acid supplement may be prevented by the suggestion that taking the supplement signals acceptance of sexual activity. Supplements also tend to be adopted more often by those who are health conscious, whereas the basic mechanisms of optimistic bias, discounting the benefits may decrease the willingness of the less health conscious to adopt folic acid supplements as part of eating behaviour.

\section{Discussion and implications}

\section{Linking nutrient intake with behaviour change mechanisms}

The objective of this paper is to explore the role of behaviour change mechanisms in inducing changes in micronutrient intake through volitional behaviour change. There are a number of behaviour change models that have been applied in promoting and explaining changes in food choices and eating behaviour. In this paper the different behaviour change mechanisms have been extracted from these models and aligned against inducing possible changes in folate intake. The novelty of this paper is the attempt to link nutrient intake with behaviour change by systematically describing the mediating food-related behaviours that are required to achieve the desired outcomes in nutrient intake. People do not 
choose nutrients, they choose foods that contain nutrients, and the reasons for these choices are rarely articulated in nutritional terms (Steptoe et al., 1995). Rather than trying to make a causal analysis, or even to give an exhaustive view of all factors influencing folate intake, this paper has attempted to reveal the challenges and possibilities of inducing behaviour changes in relation to folate intake. Naturally this approach must be applied in a specific culture and to dietary patterns within that culture but it is also important to use this approach to consider whether promoting the behaviour change is a feasible way of affecting nutrient intake.

This paper demonstrates that different models of behaviour change from a range of behavioural sciences contain similar components. Most of these models have been developed in other domains than food and their direct applicability in explaining food choices or eating behaviour has been limited. Food choices and eating behaviour differ from many other behaviours in two crucial ways: Firstly, they contain a number of small decisions that each have very little relevance, but cumulatively they add up to behaviour that has a big influence on health outcome. Secondly, these consumption behaviours are necessary and characterised by involving choices among alternatives and by extent rather than dichotomous decisions either to do or not to do something. Intervention studies in the food domain emphasise the need to use atheoretical model when planning interventions (e.g. Ammerman, Lindquist, Lohr, \& Hersey, 2002; Glanz \& Bishop, 2010; Prättälä, Roos, Hulshof, \& Sihto, 2002), but based on this paper we would argue that it is important to recognise and select the most relevant behaviour change mechanisms in relation to the desired changes in target behaviours, regardless of the origin of these mechanisms. Forcing the complexity of food-related behaviour into models that are developed in other fields of behavioural science may result in artificial actions that bear no relevance on the food domain, or alternatively omit some important factors. Dissecting the theories in order to identify the most relevant mechanisms of change provides a new approach to influencing food-related behaviours. The approach can be used to develop new combinations of policy options to target nutritional problems more efficiently, including those related to micronutrients.

\section{Mechanisms affecting behaviour}

The cognitive mechanisms that influence people's information processing and belief formation propose a number of explanations why the traditional approach of providing information to people has not always been successful in changing behaviour. In their belief formation people tend to actively process information in a way that does not threaten their existing beliefs or practices and thus have an impact on decisional balance. Although seen as factors that interfere with reasoned behaviour, these mechanisms have a functional role in information adoption. Embracing new beliefs openly without these mechanisms would impose constant re-evaluation of the decisional balance thereby requiring much effort to maintain a cognitive balance. As keeping the balance may require behaviour change, the change would become easier, but at the same time the behaviour would be less stable. Although providers of information or health promoters are aware of these mechanisms, their impact is not always recognised as constraining or facilitating targeted belief and behaviour changes. This article has tried to demonstrate how the information may be interpreted based on these mechanisms and why some messages are harder to convey than others.

Beliefs behind factors (e.g. attitudes, norms, self-efficacy) influencing intention formation must be taken into account when formulating messages. Cognitive dissonance can act as a barrier against getting the information through, but it can also be used as a tool to promote behaviour change when actively presented as a problem that needs solving. Using emotional and affective messages in changing beliefs behind attitudes may provide one way forward, although in food behaviour the perceived risk and possible negative outcomes have not influenced reported intentions to change behaviour in any strong way (e.g. Henson, Cranfield, \& Herath, 2010; Vassallo et al., 2009). Similarly social influences and norms can act as barriers or facilitators of behaviour change, but it is important to be able to link the desired changes in nutrient intake with those behaviours that are required in relation to food choices and eating. Social factors are likely to be more important in relation to meals and other structured eating occasions as these are typically enjoyed repeatedly in similar social contexts at home and at work, whereas unstructured eating occasions can vary in their social context from eating alone to sharing with friends or public eating. To effectively change unstructured eating occasions, the social context must be recognised as a factor that influences the behaviour change.

In changing food related behaviours little emphasis has been put on behaviour maintenance. Many interventions aim at changing behaviour and applying goal setting and implementation intentions, but there is less understanding of how changed behaviour can be maintained and how to support its maintenance. In part this may be due to the complexity of food-related behaviours, where differentiating between behaviour change and behaviour maintenance can be difficult. Taking supplements or not taking supplements can more easily be aligned to clearly distinguishable stages. For instance, in eating leafy vegetables as part of the meal, the maintenance can be defined as every meal, every other meal, or as three times per week.

Food choices and eating behaviour are largely habitual behaviours with repetitive low involvement choices that require very little active decision-making. From a nutritional point of view this creates an additional challenge. Hence, when translating nutrient intake into possible behavioural changes contributing to the intake, one needs to assess how such behaviours are embedded in daily routines. People tend to be unaware of decisions they make in relation to habitual behaviours. Breaking automatically cued behaviour patterns therefore requires actions that either make people more aware of their behaviours or disrupt the habitual patterns by environmental changes. Environmental changes may include monetary subsidies or affecting the availability of relevant foods in order to promote more deliberate decision-making. Often, inducing change in nutrient intake may be easier by accommodating current behaviour patterns and by changing the availability of the nutrient in products that people already eat, e.g. by folic acid fortification. In the case of folate, many countries have found this to be a more efficient way to reach sufficient levels of the nutrient. However, in other countries fortification is seen as problematic because it forces individuals to take the nutrient rather than providing them with an opportunity to make an informed choice.

\section{Limitations of the study}

The approach taken in this study has some limitations. Instead of trying to take a comprehensive approach to the complexity of food choices and eating behaviour this article has tried to unravel the puzzle of linking nutrient intake and behaviour change by using one nutrient as an example. However, using one nutrient as a starting point shows the complexity of the relationship between nutrition and behaviour in the food domain. Trying to integrate the required changes in behaviour in relation to increasing the intake of several micronutrients (e.g. iron, calcium, vitamin D) would be even more challenging. Sometimes there may also be a need to reduce the intake of a micronutrient, as is the case of sodium in many countries.

Similarly the choice of behaviour change mechanisms can be criticised as being arbitrary to some extent. However, instead of trying to cover all possible mechanisms, this article has focused on the ones that are applicable in relation to food-related 
behaviours and at the wider population level and then to describe how these mechanisms could work in the case of folate. Therefore this paper is not meant as a solution to induce behaviour change in relation to folate intake, but merely to demonstrate which factors must be considered in any specific condition where there is a discrepancy between desired and actual intake of a micronutrient and how narrowing this discrepancy can be translated into desired changes in behaviour.

In doing a general overview of choice and eating behaviour, the cultural aspects have been demonstrated by examples of possible influence. To thoroughly study the social influences one would need to do this in a culture-specific manner.

\section{Conclusions}

When considering the policy options that are most effective in producing desired outcomes in micronutrient intake, decisionmakers should consider whether the outcome can be best reached by trying to influence the behaviour of the target population, or by promoting changes in the environment, e.g. food supply, or perhaps by combining these options. Inducing changes in food-related behaviours in the target group requires understanding of the interplay between individual, social, cultural, and food-related influences on choices and eating, e.g. how habitual the behaviours are and whether social norms can be used to support desired changes (Verplanken \& Wood, 2006). Policy options that require no or only limited changes (e.g. fortification) may be considered as possible alternatives to campaigns that target individuals and their eating patterns. The folate example demonstrates the complexity of possible behavioural changes when targeting a single micronutrient and having a relatively narrowly defined main target group. The jigsaw of behaviour change and possible desired and undesired outcomes becomes much more complicated when multiple micronutrients enter the equation.

\section{References}

Ajzen, I. (1991). The theory of planned behavior. Organizational Behavior and Human Decision Processes, 50, 179-211.

Ajzen, I., \& Fishbein, M. (1980). Understanding Attitudes and Predicting Social Behavior (1st ed.). Englewood Cliffs, NJ: Prentice-Hall.

Ammerman, A., Lindquist, C., Lohr, K., \& Hersey, J. (2002). The efficacy of behavioural interventions to modify dietary fat and fruit and vegetable intake. A review of the evidence. Preventive Medicine, 35, 25-41.

Aronson, E. (1999). Dissonance, hypocrisy, and the self-concept. In E. Harmon-Jones \& J. Mills (Eds.), Cognitive Dissonance Progress on a Pivotal Theory in Socia Psychology (pp. 103-126). Washington DC: American Psychological Association.

Bandura, A. (1977a). Social Learning Theory. New York: General Learning Press.

Bandura, A. (1977b). Self-efficacy. Toward a unifying theory of behavioral change. Psychological Review, 84, 191-215.

Bandura, A. (1997). Self-Efficacy: The Exercise of Control. New York: W. H. Freeman.

Beck, A. (1976). Cognitive Therapy and the Emotional Disorders. New York: International Universities Press.

Blake, C. E., Bisogni, C. A., Sobal, J., Devine, C. M., \& Jastran, M. (2007). Classifying foods in contexts. How adults categorize foods for different eating settings. Appetite, 49(2), 500-510.

Chapman, K., \& Ogden, J. (2009). How do people change their diet? An exploration into mechanisms of dietary change. Journal of Health Psychology, 14(8), 1229-1242.

Cialdini, R. B., Kallgren, C. A., \& Reno, R. R. (1991). A focus theory of normative conduct. A theoretical refinement and re-evaluation. Advances in Experimental Social Psychology, 24, 201-234.

Conner, M., Povey, R., Sparks, P., James, R., \& Shepherd, R. (2003). Moderating role of attitudinal ambivalence within the theory of planned behaviour. British Journal of Social Psychology, 42(1), 75-94.

Conner, M., Sparks, P., Povey, R., James, R., Shepherd, R., \& Armitage, C. J. (2002). Moderator effects of attitudinal ambivalence on attitude-behaviour relationships. European Journal of Social Psychology, 32(5), 705-718.

Dwyer, J. T., Garceau, A. O., Evans, M., Li, D., Lytle, L., Hoelscher, D., et al. (2001). Do adolescent vitamin-mineral supplement users have better nutrient intakes than nonusers? Observations from the CATCH tracking study. Journal of the American Dietetic Association, 101, 1340-1346.

Festinger, L. (1957). A theory of cognitive dissonance. Evanston, IL: Row, Peterson.

Fillion, L., \& Henry, C. J. K. (1998). Nutrient losses and gains during frying. A review. International Journal of Food Sciences \& Nutrition, 49, 157-168.
Fishbein, M., Triandis, H. C., Kanfer, F. H., Becker, M., Middlestadt, S. E., \& Eichler, A. (2001). Factors influencing behavior and behavior change. In A. Baum, T. A Revenson, \& J. E. Singer (Eds.), Handbook of Health Psychology (pp. 3-17). Mahwah, NJ: Lawrence Erlbaum Associates.

Food Standards Agency., 2003. Available from <http://www.eatwell.gov.uk/ healthydiet/nutritionessentials/vitaminsandminerals/folicacid/>.

Glanz, K., \& Bishop, D. (2010). The role of behavioural science theory in development and implementation of public health interventions. Annual Review of Public Health, 31, 399-418.

Gollwitzer, P. M. (1999). Implementation intentions. Strong effects of simple plans. American Psychologist, 54, 493-503.

Gollwitzer, P. M., \& Brändstatter, V. (1997). Implementation intentions and effective goal pursuit. Journal of Personality and Social Psychology, 73, 186-199.

Gollwitzer, P. M., \& Sheeran, P. (2006). Implementation intentions and goal achievement. A meta-analysis of effects and processes. Advances in Experimental Social Psychology, 38, 249-268.

Henson, S., Cranfield, J., \& Herath, D. (2010). Understanding consumer receptivity towards foods andnon-prescription pills containing phytosterols as a means tooffset the risk of cardiovascular disease. An application ofprotection motivation theory. International Journal of Consumer Studies, 34, 28-37.

Hoek, J., \& Jones, S. (2011). Regulation, public health and social marketing. A behaviour change trinity. Journal of Social Marketing, 1(1), 32-44.

Kahneman, D., \& Tversky, A. (1979). Prospect Theory. An analysis of decision under risk. Econometrica, 47(2), 263-292.

Lindsey, L. L. M., Silk, K., von Friederichs-Fitzwater, M. M., Hamner, H. C., Prue, C. E., \& Boster, F. J. (2009). Developing effective campaign messages to prevent neural tube defects. A qualitative assessment of women's reactions to messages. Journal of Health Communication, 14, 131-159.

Lippke, S., Ziegelmann, J. P., \& Schwarzer, R. (2004). Initiation and maintenance of physical exercise. Stage-specific effects of a planning intervention. Research in Sports Medicine, 12, 221-240.

Locksmith, G., \& Duff, P. (1998). Preventing neural tube defects. The importance of periconceptional folic acid supplements. Obstetrics \& Gynecology, 91(6), 1027-1034.

Luszczynska, A., \& Schwarzer, R. (2003). Planning and self-efficacy in the adoption and maintenance of breast self-examination. A longitudinal study on selfregulatory cognitions. Psychology \& Health, 18(1), 93-108.

Maio, G., Verplanken, B., Manstead, A., Stroebe, W., Abraham, C., Sheeran, P., et al. (2007). Social psychological factors in lifestyle change and their relevance to policy. Journal of Social Issues and Policy Review, 1(1), 99-137.

Mäkelä, J., 2001. The meal format. In: Kjaernes, U. (Ed.), Eating Patterns. A Day in the Lives of Nordic People. Lysaker, Norge: SIFO: Statens institutt for forbruksforskning

McKinlay, J. B. (1975). A case for re-focusing upstream: the political economy of illness. In A. J. Enelow \& J. B. Henderson (Eds.), Applying Behavioral Science to Cardiovascular Risk (pp. 7-18). Seattle: American Heart Association.

McKinlay, J. B. (1993). The promotion of health through planned socio-political change. Challenges for research and policy. Social Science E Medicine, 36(2), 435-439.

Michie, S., Johnston, M., Abraham, C., Lawton, R., Parker, D., \& Parker, D. (2005). Making psychological theory useful for implementing evidence based practise. A consensus approach. Quality and Safety in Health Care, 14, 26-33.

Michie, S., van Stralen, M., \& West, R. (2011). The behaviour change wheel. A new method for characterising and designing behaviour change interventions. Implementation Science, 6(42), 1-11.

O'Keefe, D. J. (1990). Cognitive dissonance. In Persuasion: Theory and Research (pp. 61-78). Newbury Park, CA: Sage.

Ouelette, J., \& Wood, W. (1998). Habit and intention in everyday life. The multiple processes by which past behavior predicts future behavior. Psychological Bulletin, 124, 64-74.

Prättälä, R., Roos, G., Hulshof, K., \& Sihto, M. (2002). Food and nutrition policies and interventions. In J. Mackenbach \& M. Bakker (Eds.), Reducing Inequalities in Health: A European Perspective (pp. 104-124). London: Routledge.

Prochaska, J. O., \& DiClemente, C. C. (1983). Stages and processes of self-change of smoking. Toward an integrative model of change. Journal of Consulting and Clinical Psychology, 51, 390-395.

Prochaska, J. O., \& Velicer, W. F. (1997). The transtheoretical model of health behavior change. American Journal of Health Promotion, 12, 38-48.

Rosenstock, I. M. (1974). Historical origins of the health belief model. Health Education Monographs, 2, 1-8.

Rozin, P. (2007). Food choice: an introduction. In L. Frewer \& H. van Trijp (Eds.), Understanding Consumers of Food Products (pp. 3-29). Cambridge: Woodhead Publishing Limited.

Schwarzer, R. (2008). Modeling health behavior change. How to predict and modify the adoption and maintenance of health behaviors. Applied Psychology, 57(1), $1-29$.

Schwarzer, R., \& Renner, B. (2000). Social-cognitive predictors of health behavior. Action self-efficacy and coping self-efficacy. Health Psychology, 19(5), 487-495.

Severi, S., Bedogni, G., Manzieri, A. M., Poli, M., \& Battistini, N. (1997). Effects of cooking and storage methods on the micronutrient contents of food. European Journal of Cancer Prevention, 6, S21-S24.

Shapiro, J. M. (2005). Is there a daily discount rate? Evidence from the food stamp nutrition cycle. Journal of Public Economics, 89, 303-325.

Sheeran, P. (2002). Intention-behavior relations. A conceptual and empirical review. European Review of Social Psychology, 12, 1-36.

Simon, H. A. (1982). Models of Bounded Rationality. Cambridge, MA: MIT Press. 
1022

B.B. Jensen et al./Appetite 58 (2012) 1014-1022

Sjöberg, A., Hallberg, L., Höglund, D., \& Hulthen, L. (2003). Meal pattern, food choice, nutrient intake and life style factors in The Göteborg Adolescence Study. European Journal of Clinical Nutrition, 57, 1569-1578.

Solomons, N. W. (2007). Food fortification with folic acid. Has the other shoe dropped? Nutrition Review, 65(11), 512-515.

Sniehotta, F. F., Scholz, U., \& Schwarzer, R. (2005). Bridging the intention-behaviour gap. Planning, self-efficacy, and action control in the adoption and maintenance of physicalexercise. Psychology \& Health, 20(2), 143-160.

Sobal, J., Khan, L. K., \& Bisogni, C. (1998). A conceptual model of the food and nutrition system. Social Science \& Medicine, 47, 853-863.

Spahn, J. M., Reeves, R. S., Keim, K. S., Laquatra, I., Kellogg, M., Jortberg, B., et al. (2010). State of the evidence regarding behavior change theories and strategies in nutrition counseling to facilitate health and food behavior change. Journal of the American Dietetic Association, 110(6), 879-891.

Steptoe, A., Pollard, T. M., \& Wardle, J. (1995). Development of a measure of the motives underlying the selection of food. The food choice questionnaire. Appetite, 25, 267-284.

Thomas, K. B., Hawser, K., Rodriguez, N. Y., \& Quinn, G. P. (2010). Folic acid promotion for Hispanic women in Florida. A vitamin diary study. Health Education Journal, 69(3), 344-352.

Triandis, H. C. (1977). Interpersonal Behavior. Monterey: Books/Cole.

Vassallo, M., Saba, A., Arvola, A., Dean, M., Messina, F., Winkelmann, M., et al. (2009). Willingness to use functional breads. Applying the Health Belief Model across four European countries. Appetite, 52, 452-460.
Verplanken, B., \& Fess, S. (1999). Good intentions, bad habits, and effects on forming implementation intentions on healthy eating. European Journal of Social Psychology, 29, 591-604.

Verplanken, B., \& Wood, W. (2006). Changing and breaking consumer habits. Journal of Public Policy and Marketing, 25, 90-103.

Warnick, E., Dearden, K. A., Slater, S., Butrón, B., Lanate, C. F., \& Huffman, S. L. (2004). Social marketing improved the use of multivitamin and mineral supplements among resource-poor women in Bolivia. Journal of Nutrition Education and Behavior, 36(6), 290-297.

Weinstein, N. D. (1984). Why it wont happen to me. Perceptions of risk factors and illness susceptibility. Health Psychology, 3, 431-457.

Weinstein, N. D., \& Sandman, P. M. (1992). A model of the precaution adoption process. Evidence from home radon testing. Health Psychology, 11(3), 170-180.

WHO., 2011. Global status report on noncommunicable diseases. Available from <http://whqlibdoc.who.int/publications/2011/9789240686458_eng.pdf>.

Wood, W., \& Neal, D. T. (2009). The habitual consumer. Journal of Consumer Psychology, 19, 579-592.

Wood, W. L., Tam, L., \& Guerrero Witt, M. (2005). Changing circumstances, disrupting habits. Journal of Personality and Social Psychology, 88(6), 918-933.

WRAP., 2009. Household food and drink waste in the UK. Available from <http:// www.wrap.org.uk/downloads/Household_food_and_drink_waste_in_the_UK__report.a648b79c.8048.pdf>. 